\title{
Credit Markets and the Propagation of Monetary Policy Shocks*
}

\author{
Radim Boháček ${ }^{\dagger}$ \\ CERGE-EI \\ Hugo Rodríguez Mendizábal ${ }^{\ddagger}$ \\ Universitat Autònoma de Barcelona and centrA
}

January 16, 2005

\begin{abstract}
This paper analyzes the propagation of monetary policy shocks through the creation of credit in an economy. Models of the monetary transmission mechanism typically feature responses which last for a few quarters contrary to what the empirical evidence suggests. To propagate the impact of monetary shocks over time, these models introduce adjustment costs by which agents find it optimal to change their decisions slowly. This paper presents another explanation that does not rely on any sort of adjustment costs or stickiness. In our economy, agents own assets and make occupational choices. Banks intermediate between agents demanding and supplying assets. Our interpretation is based on the way banks create credit and how the monetary authority affects the process of financial intermediation through its monetary policy. As the central bank lowers the interest rate by buying government bonds in exchange for reserves, high productive entrepreneurs are able to borrow more resources from low productivity agents. We show that this movement of capital among agents sets in motion a response of the economy that resembles an expansionary phase of the cycle.
\end{abstract}

${ }^{*}$ We would like to thank Jim Costain, Carlos Perez Verdia and Galina Vereshchagina for very helpful comments and suggestions. Financial support from the Spanish Ministry of Education and Science and FEDER through grant SEC2003-00306 is gratefully acknowledged. All remaining errors are ours.

${ }^{\dagger}$ CERGE-EI, Politickych veznu 7, 11121 Prague 1, Czech Republic. Email: radim.bohacek@cerge-ei.cz

${ }^{\ddagger}$ Departament d’Economia i Historia Economica. Edifici B. Universitat Autònoma de Barcelona. 08193 Bellaterra Barcelona, Spain. E-mail: hugo.rodriguez@uab.es. 
JEL Classification: E50

Keywords: Credit, Monetary policy shock, Heterogeneous agents

\section{Introduction}

This paper analyzes the propagation of monetary policy shocks through the creation of credit in an economy. There is a vast literature on the transmission mechanism of monetary shocks. The empirical strand of this literature has identified two stylized facts about the response of macroeconomic variables to unexpected changes in the monetary conditions of the economy:

1. Monetary policy shocks may have sizeable impacts on aggregate activity; and,

2. These effects propagate over time, with responses of macroeconomic variables having a hump shape that peaks at four to six quarters after the shock.

There is a growing theoretical literature that tries to build up models to generate these two empirical facts. Usually, the modeling choices are as follows. To get monetary policy to affect the real activity in the short run, some sort of friction in the model is needed. This is accomplished by assuming that agents cannot adjust in the short run some nominal variable such as prices, wages or the asset composition of portfolios. It is typical in models with these features that responses are immediate and last for a few quarters only. To propagate the impact of monetary shocks over time, these models introduce adjustment costs by which agents find it optimal to change their decisions slowly.

This paper presents another explanation of the two stylized facts mentioned above that does not rely on any sort of stickiness or adjustment costs. Our interpretation is based on the way credit is created and how the monetary conditions in an economy affect the process of financial intermediation. In our economy, there is a population of agents who accumulate assets and choose between two different occupations. On the one hand, an agent may decide to be a worker which means he will provide labor services and lend out his assets. On the other hand, an agent may decide to be an entrepreneur. In this case, he will need to finance an investment plan but will face financial constraints in the form of collateral for the project. Agents face idiosyncratic productivity shocks which generate an endogenous distribution of assets within the population. Because we assume decreasing returns to scale, the inability of some entrepreneurs to achieve their optimal firm size due to the financial constraint will result in an inefficient allocation of resources.

In this economy, capital is distributed among agents through the use of nominal units of account created by financial intermediaries. Entrepreneurs with a low 
level of assets borrow these units of account to obtain extra capital for their firms. In this sense, the nominal interest rate represents a cost of production. When creating credit, banks have to satisfy reserve requirements. The monetary authority provides these banks with two types of liabilities: reserves and bonds. We show that the relevant policy variable to determine the level of interest rates is the ratio of liquid (reserves) to illiquid (bonds) liabilities of the central bank.

One of the crucial features that allows monetary shocks in our model to generate a sizeable contemporaneous response of output is the existence of idle capital. There are several possible interpretations to rationalize the presence of unused resources. One is the limitations firms may encounter to modify their capacity to produce goods in the short run. This may happen if firms face uncertainty about demand at the time of capacity choices, an idea developed, among others, by Fagnart, Licandro and Portier [11] and applied to a monetary environment by Alvarez Lois [1]. This also may happen if there are costs of producing at full capacity. To make our model simple, we pursue another interpretation. In our model, the government needs to finance its liabilities. In the process it bids up the interest rate and absorbs assets which otherwise would have ended up in the production sector financing the use of productive capital.

An expansionary monetary policy is associated with an increase of reserves over bonds. Financial intermediaries learn that the supply of reserves have increased which gives them the possibility of expanding credit. However, the government is borrowing less through debt so banks will have to give these credits to entrepreneurs. Given that the interest rate is a cost to entrepreneurs borrowing credits, the only way to convince them to borrow more is by reducing the lending rate. This change produces several effects. First, some of the idle assets that were not used before are now available to finance productive capital. Also, lower interest rates make constrained firms borrow more and resources are moved from entrepreneurs with low productivity to high productive ones. As the economy adjusts to the new environment, aggregate variables behave in a way that resembles an expansionary phase of the cycle.

We understand this mechanism depends on the existence of idle assets due to the presence of reserves and bonds. However, we believe it should apply independently of the reason why a proportion of the productive capacity of the economy is not used to start with. The reason is that our mechanism works through a channel which is present in any of these other interpretations, namely, an expansionary monetary shock makes it cheaper to finance the use of productive capital and, therefore, will push the economy towards a more intensive utilization of these resources.

Since the seminal contribution of Bernanke and Gertler [2], a strand of the literature has analyzed the macroeconomic implications of financial frictions with models where financial constraints arise endogenously (see, among others, Bernanke, 
Gertler and Gilchrist [3], Carlstrom and Fuerst [7], Fuerst [12], Hubbard [13], and Kiyotaki and Moore [15]). These papers, however, are representative agents models. More recently, several papers study economies where financial constraints interact with firms heterogeneity. In these models the endogenous distribution of capital across firms is an important element in the aggregate properties of the economies analyzed. In particular, Cooley et al. [9] develop a model with heterogeneous entrepreneurs subject to financial constraints to study the role of repudiation of financial contracts for the diffusion and propagation of technological progress. Jermann and Quadrini [14] use the same model as Cooley et al. [9] to analyze the effects of an improvement of expectations about technological innovations. They show that just the prospects of an increase in the growth of productivity can generate an expansionary episode because of the benefits from reallocating capital between constrained and unconstrained firms.

In another paper related to ours, Kiyotaki and Moore [16] analyze the business cycle properties derived from monetary policy shocks. They are also able to generate an endogenous distribution of firms but the mechanism is different from ours. The main focus of their paper is to have money demanded from first principles. To obtain that, investors in their economy receive random opportunities to produce new capital goods from consumption goods. These idiosyncratic shocks generate the heterogeneity across investors and the need to transfer funds from the agents without investment opportunities to the ones who have them. However, old capital is illiquid in the sense that it cannot be fully used to finance these investment projects. Under these circumstances, money may have a value in such an economy since it can speed up trade among agents. The authores then look at the qualitative properties of the dynamic response of the economy to technology and monetary shocks but do not perform any quantitative analysis.

Another paper that is close to ours is Cooley and Quadrini [10]. These authors construct a model where firms heterogeneity results from borrowing limits on the funds needed by firms to expand their business. The model incorporates a nominal sector and a limited participation constraint on the part of households when deciding their deposits at financial intermediaries. This constraint allows the central bank to affect the nominal interest rate in the short run and to induce a persistent movement in output through the financial decisions of firms. They find that although quantitatively the aggregate impact is small, the response of small and large firms differs substantially.

The transmission mechanism in our model is similar to the one in Cooley et al. [9], Jermann and Quadrini [14], and Monge [20]. That is, a financial constraint makes entrepreneurs with low levels of assets run their firms at a smaller size than what is optimal. Thus, any perturbation that reduces the cost of capital is expansionary and, as assets take time to accumulate, the response of constrained firms propagate over time. However, compared with these three papers, we concentrate 
on nominal, monetary policy shocks. Unlike Kiyotaki and Moore [16], we motivate a demand for nominal units of account through a cost of information gathering argument similar to the one proposed by Lucas [18]. As in Cooley and Quadrini [10], we assume imperfect capital markets in the form of an endogenous borrowing limit but we do not need a limited participation constraint for the monetary authority to affect the nominal interest rate. Instead, the central bank introduces a reserve requirement which regulates the amount of intermediation in the economy. We want to stress that by carefully modelling the nominal side of the economy, there is no need to impose stickiness on any variable since the economy propagates shocks by itself. Furthermore, we provide our agents with an occupational choice to decide whether to become a worker or an entrepreneur. This modelling strategy allows us to examine the role that endogenizing the extensive margin of investment decisions has for the monetary transmission mechanism.

The paper is organized as follows. Section 2 presents some new evidence on the effects of monetary shocks on economic activity. Section 3 describes the model. Section 4 presents the numerical simulations and section 5 concludes.

\section{The Effects of Monetary Shocks on Economic Activity}

The empirical literature on the monetary transmission mechanism has concluded that an expansionary monetary shock drives down nominal interest rates which makes output rise. The price level responds slowly to these changes and ends up increasing in the long run. Although there is a general consensus about these qualitative effects, the profession has yet to agree on a single set of identification restrictions to isolate monetary shocks in the data and, therefore, the quantitative estimations of these effects vary widely across papers.

Figure 1 presents the responses of the capacity utilization rate, the growth rate of the GDP deflator and the 3-month T-bill rate to a monetary shock that occurs at period 1. These responses are estimated using the scheme employed in Menner and Rodríguez Mendizábal [19]. ${ }^{1}$ The identification strategy is based on the sign restrictions of the responses of these variables to three different types of shocks (demand, supply and monetary) imposed by theory. Because all three variables are percentages, the responses are measured as differences with respect to average values. So, for example, an expansionary monetary shock that reduces the interest rate by 50 basis points, raises capacity utilization from its average of 81.15 percent to 81.40 percent or 0.25 percentage points. For comparison purposes, the figure also includes the responses estimated with the identification scheme used in Christiano, Eichenbaum and Evans [8] (CEE) which represents a method widely

\footnotetext{
${ }^{1}$ The sample covers from the first quarter of 1960 to the first quarter of 2003 (173 observations).
} 
used in the literature. ${ }^{2}$

One difference between the two schemes is that capacity utilization and prices are restricted not to respond contemporaneously to a monetary shock in the CEE estimation. However, we provide an alternative to the estimation by CEE since, as Canova and Pina [6] show, it is very hard to rationalize theoretically the zero restrictions imposed by triangular identification schemes. Any theoretical model, including the one described below, predicts all endogenous variables to have nonzero contemporaneous correlations through the impact of the fundamental shocks. As the sign restriction method shows, once the zero restrictions are relaxed a monetary shock can have important contemporaneous effects on real variables such as the capacity utilization rate.

Nevertheless, we observe the two estimations to be fairly similar both in size and persistence of the responses. In particular, the sign restriction estimation implies that an expansionary monetary shock is associated with a reduction of interest rates of about 50 basis points on impact and this variable stays below average for about 9 quarters. This movement in interest rates is accompanied by a sizeable and persistent effect on capacity utilization with a peak at around 7 quarters where the use of installed capacity rises by 0.7 percentage points. Finally, prices react slowly.

Table 1 provides evidence on a possible channel through which the monetary shock operates. It presents the results from regressing two policy variables, namely the growth rate of the Fed holdings of government securities (FEDSEC) and the growth rate of nonborrowed reserves (NBR), on a constant, four lags and the monetary shock estimated through the sign restriction scheme described in the previous paragraphs. A monetary shock that unexpectedly reduces interest rates generates a statistically significant increase in both, the Federal Reserve holdings of government securities as well as nonborrowed reserves. ${ }^{3}$ This finding supports the idea that a monetary shock is associated with a change in the assets and liabilities composition of the Fed's balance.

In the next section we build a model to capture these empirical facts. In our economy real assets may be used as productive capital. Agents with low levels of wealth borrow assets using units of accounts created by commercial banks.

\footnotetext{
${ }^{2}$ For the CEE identification scheme a six variable VAR(4) was estimated which included, in the following order, capacity utlization, the growth rate of the GDP deflator, the growth rate of a commodity price index, the federal funds rate, the growth rate of nonborrowed reserves and the growth rate of total reserves. The monetary shock estimated with this scheme has a correlation of 71 percent with the shock estimated with the sign restriction approach.

${ }^{3}$ These results are robust to a wide variety of specifications that include the variables in levels as well as other sources of shocks.
} 
However, the process of intermediation makes some of these assets to remain idle. This is due to the government and the central bank using some of these units of account. We interpret the ratio of productive capital to real assets as capacity utilization. Furthermore, the central bank in our model has the ability to affect the proportion of assets employed as capital by changing the amount of units of accounts used in the financial sector. Monetary policy is conducted by buying and selling government bonds in exchange for reserves which commercial banks need in order to intermediate between borrowers and lenders. In this way, we deviate from standard macro models that assume central banks to directly control broad monetary aggregates. Instead, we distinguish between narrow and broad definitions of money and incorporate a more realistic implementation of monetary policy through the use of open market operations. We show this addition has important implications for the neutrality of money.

\section{The Model}

The model is a nominal version of Boháček [5]. In this economy there is a continuum of agents with mass one. These individuals may differ in the amount of accumulated assets and in their productivities. Each agent has access to a decision on whether to allocate his talent to an entrepreneurial activity or to use it as a worker. There is also a corporate banking sector in the business of intermediating between agents with an excess of funds and agents with liquidity needs. Finally, there is a central bank that designs monetary policy.

Each agent is endowed with a unit of time and evaluates streams of consumption $\left(c_{t}\right)$ with the utility function

$$
E\left[\sum_{t=0}^{\infty} \beta^{t} u\left(c_{t}\right)\right],
$$

where $\beta \in(0,1)$ and $u: \Re_{+} \rightarrow \Re$ is a bounded, strictly increasing, strictly concave, and twice differentiable continuous function that satisfies the Inada conditions. At the beginning of every period, agents are identified by a level of accumulated assets $a \in A=[0, \infty)$ and by an idiosyncratic productivity shock $z \in Z=[\underline{z}, \bar{z}]$. This productivity level is carried from the previous period and represents a signal for the effective productivity the agent will have later in the period when production takes place, $z^{\prime} \in Z$.

The timing of events is as follows. First, the central bank decides on the monetary policy stance defined as the composition of government liabilities. Second, agents make an occupational choice and decide whether to be a worker or an entrepreneur. Workers deposit their assets at the financial intermediaries and offer 
their labor services in the market. Entrepreneurs decide how much capital and labor to demand. Banks are in the business of intermediating between suppliers of capital, that is, all workers as well as the entrepreneurs with assets in excess of their investment needs, and demanders of capital, that is, entrepreneurs who want to expand their business above the level of their accumulated assets. Finally, at the end of the period, productivities for the period $\left(z^{\prime}\right)$ are realized and production takes place. Then, workers are paid their wages, entrepreneurs realize profits and interests are paid on loans and deposits.

If an agent decides to be a worker, he will draw his effective skill, $z^{\prime}$, from a fixed distribution $\psi\left(z^{\prime}\right)$. The revenue from working is $z^{\prime} w$ where $w$ is the wage per unit of productivity. Each agent who decides to be entrepreneurs will draw his productivity level from a Markov process with transition function $Q\left(z, z^{\prime}\right)$. The Markovian nature of the entrepreneurial skills is assumed to reflect the learning aspects of entrepreneurial activity as documented by Quadrini [21]. Furthermore, we assume $Q$ to be monotone and to satisfy the Feller property. Entrepreneurs hire capital $(k)$ and labor $(n)$ in a competitive fashion and produce according to the production function

$$
y=z^{\prime} f(k, n)=z^{\prime}\left(k^{\alpha} n^{1-\alpha}\right)^{\theta},
$$

where $\alpha \in(0,1)$ and $\theta<1$. The production function exhibits decreasing returns to scale which, as in Lucas [17], can be thought of as capturing the presence of decreasing returns to managerial control. Capital used in production depreciates at the rate $\delta \in(0,1)$. The productivity shocks are drawn from the same set $Z=[\underline{z}, \bar{z}]$, both for workers and entrepreneurs. It is assumed that entrepreneurs with the lowest signal remain with that level of productivity $[Q(\underline{z}, \underline{z})=1]$, so that those agents always prefer to become workers. To guarantee that some entrepreneurs exit that occupation, we also assume that $Q(z, \underline{z})>0$, for all $z \in Z$.

Given the distribution of assets and productivities among agents, there will be some of them who will not want to use all their assets. These are all the workers and the entrepreneurs who expect to have low relative levels of productivity or who have relative high levels of initial assets. On the other hand, entrepreneurs who expect to be very skillful but have relatively low levels of assets will like to use more capital than what they can finance by themselves. The commercial banks are in the business of connecting people expecting to have idle assets with people who want to expand their firms above the level of their accumulated assets. One problem in this economy is that workers cannot take their assets to where they work. So, some of the workers may be working with an entrepreneur who does not borrow at all or who borrows from other agents. Also, there may be entrepreneurs 
lending to other entrepreneurs. This means some agents in this economy may be lending assets to some other agents they never see.

One additional difficulty is that there is a continuum of these agents. Banks have to keep track of all the capital exchanges among agents, and this may be expensive. As in Lucas [18], one possibility that reduces the cost of following borrowing and lending is to record balances only and to forget about the information of who borrows from whom. These balances are maintained in a unit of account called "credit" created by banks in the process of intermediation. Entrepreneurs in need of capital borrow these units of account to rent capital from the rest of agents who deposit these credits in accounts at the bank. These credits exchange for capital goods at a nominal price $P$. Depositors receive a nominal rate $R^{D}$ per credit deposited and borrowers pay a nominal rate $R^{L}$ per credit borrowed. When these rates are received, the credits are exchanged for capital goods at the price $P$. At the beginning of each period, the representative bank has a supply $D$ of these credits to be determined below. Also notice that, when production takes place, workers are in the firms to collect the goods so there is no need for a medium of exchange for consumption goods and wages.

There are two costs of being an entrepreneur. On the one hand, there is the opportunity cost of foregone wages which represent an endogenous barrier to entry for entrepreneurs. In this sense, it will determine a minimum size of the firm below which it is more profitable to become a worker. On the other hand, we assume full information and no possibility of default in financial contracts. ${ }^{4}$ Because the sizes of the firms have to be chosen before effective skills for the period are known, there is always the risk of drawing a low productivity shock and realizing negative profits that have to be paid for with the entrepreneur's own assets. The Inada assumption for the utility function together with default not being possible force entrepreneurs to guarantee that consumption is strictly positive for all realizations of the productivity shock. Thus, when deciding the dimension of the firm an entrepreneur may be constrained by the amount of accumulated assets which serve as collateral to cover potential negative profits in case the entrepreneur is unlucky enough and draws the lowest productivity shock. Since we assume that $Q(z, \underline{z})>0$ for all $z \in Z$, all entrepreneurs will need to have some collateral when financing investment projects.

After the labor income and profits are realized, agents decide on how much to consume $(c)$ and the amount of physical assets $\left(a^{\prime}\right)$ that they will take to next period. This period's shock $z^{\prime}$ is also carried as next period's signal for future productivity shocks. The problem of an agent who enters the period with the pair

\footnotetext{
${ }^{4}$ This could be motivated by the existence of limited commitment on the part of borrowers in repaying the loans as in Cooley et al. [9].
} 
$(a, z)$ can be summarized by the value function

$$
v(a, z)=\max \left\{\int v^{W}\left(a, z^{\prime}\right) \psi\left(d z^{\prime}\right), \max _{k, n} \int v^{E}\left(a, z^{\prime}\right) Q\left(z, d z^{\prime}\right)\right\},
$$

where

$$
v^{i}\left(a, z^{\prime}\right)=\max _{c, a^{\prime}}\left[u(c)+\beta v\left(a^{\prime}, z^{\prime}\right)\right]
$$

with $i=W, E$ indexing the type of agent, either worker $(W)$ or entrepreneur $(E)$. The worker's budget constraint is

$$
c+a^{\prime} \leq(1-\delta) a+\frac{R^{D} P a}{P}+w z^{\prime}
$$

or

$$
c+a^{\prime} \leq(1-\delta) a+R^{D} a+w z^{\prime}
$$

where $w$ is the real wage. For the entrepreneur, the budget constraint is

$$
c+a^{\prime} \leq(1-\delta) a+\pi^{E}
$$

with real profits equal to

$$
\pi^{E}=z^{\prime} f(k, n)-w n+\frac{R^{D} \max [0, P a-P k]}{P}-\frac{R^{L} \max [0, P k-P a]}{P},
$$

or

$$
\pi^{E}=z^{\prime} f(k, n)-w n+R^{D} \max [0, a-k]-R^{L} \max [0, k-a] .
$$

Notice agents make their occupational and production decisions after observing the market interest rates $R^{D}$ and $R^{L}$ but before their productivities $\left(z^{\prime}\right)$ are realized for the period. When deciding on the size of the firm, the entrepreneur has to satisfy the financial constraint

$$
w n+R^{L} \max [0, k-a]<(1-\delta) a+\underline{z} f(k, n)+R^{D} \max [0, a-k]
$$

by which it is ensured that the production costs are covered even for the lowest productivity level. Thus, an agent with an initially low level of assets $(a)$ but with the prospects of having good skills (a high expected $z^{\prime}$ ) may not be able to reach the optimal size of the firm because of the possibility of drawing a low realization of his productivity and realizing negative profits he will not be able to cover with his accumulated assets. 
Summarizing, each period agents first make decisions based on their individual state $(a, z)$ and the prices of the economy. These decisions are whether to become a worker or an entrepreneur and the amount of labor, $n(a, z)$, and capital, $k(a, z)$, to hire. Then, after productivity for the period $\left(z^{\prime}\right)$ is revealed, they decide how much to consume, $c\left(a, z^{\prime}\right)$, and how many assets to transfer to the next period, $a^{\prime}\left(a, z^{\prime}\right)$. At the aggregate level, the equilibrium outcome of these decisions is a probability measure $\lambda$ that determines the density of agents with each combination of productivities $z$ and capital $a$. This measure evolves as

$$
\lambda^{\prime}\left(\mathcal{A}^{\prime}, \mathcal{Z}^{\prime}\right)=\int_{S} \Delta\left(z, d z^{\prime}\right) \lambda(d a \times d z)
$$

where $S=\left\{\left(a, z^{\prime}\right): a^{\prime}\left(a, z^{\prime}\right) \in \mathcal{A}^{\prime}\right.$ and $\left.z^{\prime} \in \mathcal{Z}^{\prime}\right\}$ and $\Delta$ is a transition selector

$$
\left.\Delta\left(z, d z^{\prime}\right) \equiv Q\left(z, d z^{\prime}\right)\right|_{E}+\left.\psi\left(d z^{\prime}\right)\right|_{W}
$$

that determines the end of period productivities from the beginning of period productivities. This transition selector is endogenous because how productivities change within the period is different between workers and entrepreneurs, and this occupational choice is a decision of the agents. So, from the law of motion of $\lambda$ the measure of agents with next period's state in the set $\left(\mathcal{A}^{\prime}, \mathcal{Z}^{\prime}\right)$ are those whose skills evolve to the set $\mathcal{Z}^{\prime}$ and whose optimal decision is to accumulate assets that belong to the set $\mathcal{A}^{\prime}$.

The problem of the banking sector is to maintain the nominal portfolio of the economy. The balance sheet of a representative bank is

$$
D=L+H^{d}+B^{d}
$$

where $D$ are deposits (sources of funds for the bank), $L$ denotes the loans to entrepreneurs, $H^{d}$ is the demand for reserves at the central bank, and $B^{d}$ represents certificates of deposits and other forms of lending to the public sector. Reserves earn no interest. Banks have to hold them because there is a requirement that links the amount of deposits they can provide with the amount of reserves they own $^{5}$

$$
H^{d}=\rho D .
$$

${ }^{5}$ The reserve requirement can be interpreted in literal terms for countries where this regulation is in place or as a reserve demand for settlement accounts for payment systems in countries without such a rule. 
Certificates of deposits are remunerated at the nominal rate $R^{B}$. Banks are risk neutral and the financial sector is competitive. So, the problem of a representative bank is to maximize profits from intermediation

$$
\max _{L, B^{d}, D, H^{d}} \Pi^{I}=R^{L} L+R^{B} B^{d}-R^{D} D
$$

subject to

$$
D=L+H^{d}+B^{d}
$$

and

$$
H^{d}=\rho D
$$

Because of the financial constraint imposed on borrowers, banks face no risk. Also, the problem of the bank shows the role of government liabilities. Reserves are used to expand deposits. On the other hand, certificates of deposits deviate units of accounts from the private sector's financing of firms to the central bank. This implies that some of the assets deposited in the financial intermediary will remain idle in the sense that they will not be used by entrepreneurs to acquire productive capital. Bank optimization implies

$$
\frac{R^{D}}{1-\rho}=R^{B}=R^{L}
$$

Finally, the central bank decides on the composition of its nominal liabilities. At the beginning of each period, the central bank supplies the economy with $H$ units of liquid assets (reserves) and $B$ units of illiquid assets (certificates of deposits). Call $X=H+B$, the total liabilities of the central bank. We assume the central bank increases government liabilities to pay for the interest rates of its certificates of deposits. The budget constraint of the central bank is then,

$$
X^{\prime}=X+R^{B} B
$$

The decision of the central bank is the composition of the new liabilities, that is, how to split $X^{\prime}$ between $H^{\prime}$ and $B^{\prime}$.

\subsection{The stationary equilibria}

We first look at the determination of the stationary equilibria. Since nominal variables are growing, it will be convenient to normalize them by the total level 
of government liabilities, $X$. Such normalized variables will be denoted by lower case letters. So, define

$$
h=\frac{H}{X} ; b=\frac{B}{X} ; p=\frac{P}{X},
$$

with $h+b=1$. At a steady state, the central bank keeps $h$ and $b$ fixed forever. This means, all liabilities of the central bank, together with all nominal variables, grow at the same rate equal to

$$
\mu=\frac{H^{\prime}+B^{\prime}}{H+B}=1+\frac{R^{B} B}{H+B}=1+R^{B} b .
$$

Notice that the central bank does not pursue policies where its liabilities grow exogenously. The growth rate of these liabilities, $\mu$, and therefore the inflation rate, is linked to the interest rate and the number $h$. There is also a stationary probability measure $\lambda$ that determines the density of agents with each combination of productivities $z$ and capital $a$. So, this measure should satisfy

$$
\lambda\left(\mathcal{A}^{\prime}, \mathcal{Z}^{\prime}\right)=\int_{S} \Delta\left(z, d z^{\prime}\right) \lambda(d a \times d z)
$$

with $S=\left\{\left(a, z^{\prime}\right): a^{\prime}\left(a, z^{\prime}\right) \in \mathcal{A}^{\prime}\right.$ and $\left.z^{\prime} \in \mathcal{Z}^{\prime}\right\}$ and $\Delta$ being the transition selector defined above.

With these elements, we can define the steady state of this economy.

Definition 1 A stationary recursive competitive equilibrium is constant prices $\left(R^{D}, R^{L}, R^{B}, w, p\right)$, a constant growth rate for nominal prices $\mu$, value functions $\left[v(a, z), v^{W}(a, z), v^{E}(a, z)\right]$, policy functions [ $\left.k(a, z), n(a, z), c\left(a, z^{\prime}\right), a^{\prime}\left(a, z^{\prime}\right)\right]$, a probability measure $(\lambda)$ and a transition selector $\left[\Delta\left(z, d z^{\prime}\right)\right]$ such that given the policy of the central bank $(h, b, \rho)$,

1. at given prices the policy functions solve the optimization problem of each agent $(a, z)$,

2. the probability measure $\lambda$ is time invariant,

3. the aggregate asset level is constant

$$
A \equiv \int a^{\prime}\left(a, z^{\prime}\right) \Delta\left(z, d z^{\prime}\right) \lambda(d a \times d z)=\int a \lambda(d a \times d z) .
$$


4. markets clear: labor,

$$
\int_{W} z^{\prime} \Delta\left(z, d z^{\prime}\right) \lambda(d a \times d z)=\int n(a, z) \lambda(d a \times d z),
$$

deposits,

$$
\frac{1}{\rho} h=p \int_{W} a \lambda(d a \times d z)+p \int_{E} \max [0, a-k(a, z)] \lambda(d a \times d z),
$$

and loans,

$$
\left(\frac{1}{\rho}-1\right) h-b=p \int_{E} \max [0, k(a, z)-a] \lambda(d a \times d z),
$$

5. the aggregate feasibility constraint holds at equality

$$
\begin{array}{r}
\int\left[c\left(a, z^{\prime}\right)+a^{\prime}\left(a, z^{\prime}\right)\right] \Delta\left(z, d z^{\prime}\right) \lambda(d a \times d z) \\
=\int(1-\delta) a \lambda(d a \times d z)+\int z^{\prime} f[k(a, z), n(a, z)] Q\left(z, d z^{\prime}\right) \lambda(d a \times d z)
\end{array}
$$

6. and the gross growth rate of nominal prices is

$$
\mu=1+R^{B} b
$$

Of course, by Walras' Law, one of these conditions is redundant. In this definition, it is implicit that the markets for central bank's certificates of deposits and reserves clear. Once we know these variables, the price level is determined from

$$
P=X p
$$

Notice also the model is neutral with respect to changes in government liabilities as long as the central bank changes certificates of deposit and reserves proportionally. That is, for any proportional change in $(H, B)$, individual decisions are not affected, so the equilibrium is the same in terms of real or normalized variables and the only difference is a change in the nominal price level $P$. One way to see the determination of the price level is as a ratio of the units of account 
loaned to entrepreneurs with respect to the capital they obtain with those units of account. In other words, from (5) we have that

$$
P=\frac{L}{\int_{E} \max [0, k(a, z)-a] \lambda(d a \times d z)} .
$$

The total supply of units of account is determined from the balance sheet of commercial banks,

$$
\left(\frac{1}{\rho}-1\right) H=L+B
$$

where we have used (3) to substitute for deposits in equilibrium. That is, total units of account serve to finance either the use of capital by entrepreneurs $(L)$ or government debt $(B)$. On the other hand, the supply of real assets to be used for capital only depends upon the interest rates $R^{D}$ and $R^{L}$. A proportional increase in government liabilities ( $H$ and $B$ ) implies a proportional increase in the supply of loans which support the same allocation of real assets and the same equilibrium provided nominal prices increase also proportionally.

We can also see that there is a continuum of stationary equilibria indexed by the reserve to total government liabilities ratio, the number $h$, as well as the reserve requirement $\rho$. Different values of the pair $(h, \rho)$ are associated with stationary equilibria with different proportions of government liabilities, different interest rates, different price levels and different inflations. At one extreme, as $\rho$ goes to 0 and $h$ goes to 1 the model converges to the real economy of Boháček [5]. Keeping $h=1$, as we increase $\rho$, we introduce a gap between borrowing and lending rates and one of the frictions that reduce financial intermediation appears. On the other hand, keeping $\rho$ constant, as we start decreasing $h$, the central bank takes nominal resources from the economy and there are less credits to be used to finance capital acquisitions. For that to be the case, and in order to convince savers to give their credits to the central bank, rates must go up. In the limit, when $h$ is 0 , we go to autarchy (in this case, there is no intermediation). Thus, keeping $\rho$ constant, an increase in $h$ should be associated with a steady state where interest rates are lower. It turns out that for low values of $\rho$, such as the one used in the calibration exercise we conduct, the stationary interest rate is close to the value in Boháček [5] for most of the values of $h$. Below we analyze the transition between these steady states.

\subsection{The occupational choice}

In this economy, agents have to make the occupational choice given the interest rates $\left(R^{L}, R^{D}\right)$, the real wage $(w)$ and the individual characteristics summarized 
by the accumulated level of assets $(a)$ and the productivity signal $(z)$. The occupational choice is made by comparing the expected present discounted utility obtained from being a worker with that of being an entrepreneur subject to the financial constraint (2). To guarantee the existence of a stationary recursive equilibrium with a positive fraction of the population in each occupation we need to impose the next two assumptions:

Assumption 1. The upper bound for the signal ability shock, $\bar{z}$, is such that there exists an asset level $a^{s}$ for which

$$
\int v^{W}\left(a, z^{\prime}\right) \psi\left(d z^{\prime}\right) \leq \int v^{E}\left(a, z^{\prime}\right) Q\left(\bar{z}, d z^{\prime}\right)
$$

for all $a \geq a^{s}$.

Assumption 2. The lower bound for the signal ability shock, $\underline{z}$, is such that

$$
\int v^{W}\left(a, z^{\prime}\right) \psi\left(d z^{\prime}\right) \geq \int v^{E}\left(a, z^{\prime}\right) Q\left(\underline{z}, d z^{\prime}\right)
$$

for all $a \in A$.

The first assumption requires a sufficiently high productivity shock so that agents with accumulated assets above a threshold value $a^{s}$ become entrepreneurs. This is because the expected value of creating a firm is larger than the expected value of being a worker. The second assumption imposes the opposite condition. If an agent receives the lowest signal, he will always choose to become a worker independently of his accumulated asset level or prior occupation.

The properties of the value functions $v(a, z), v^{W}(a, z)$, and $v^{E}(a, z)$ depend upon the assumptions on the transition functions $\psi$ and $Q$ and the utility function that follow the analysis in Stokey, Lucas and Prescott [22]. All value functions, $v^{i}\left(a, z^{\prime}\right)$ for $i=E, W$, are increasing in both arguments since the utility function is strictly increasing and strictly concave and the agent's constraint set is strictly increasing in assets and the ability shock. Furthermore, the expected value for workers is independent of the productivity $z$ and is an increasing and continuous function of $a$. On the other hand, the expected value function of entrepreneurs is an increasing and continuous function of both $a$ and $z$. This is due to the assumption on $Q$ being monotone and satisfying the Feller property. Finally, the value function $v(a, z)$ is non-decreasing in $z$ and strictly increasing in $a .^{6}$ The properties of the value function together with assumptions 1 and 2 ensure that for

${ }^{6}$ The value function $v(a, z)$ is the outer envelope for the value functions at each shock level and may not be a concave function even if the value functions of workers and entrepreneurs are. The operator on the value function satisfies Blackwell's sufficient conditions for a contraction mapping. 
all levels of the signal $z$ there is either none or at most one level of accumulated assets $a^{s}(z)$ above which agents become entrepreneurs.

\subsection{Entrepreneurial decisions and financial intermediation}

As mentioned above, entrepreneurs have to decide on the size of their firms before they know their productivity levels for the period. Given the assumed properties of the utility function and the assumptions of full information and no possibility of default, any entrepreneur will choose productive capital, $k$, and labor, $n$, so that consumption levels are nonnegative for all possible realizations of shocks. This means that entrepreneurial decisions are taken so that

$$
w n+R^{L} \max [0, k-a] \leq(1-\delta) a+\underline{z} f(k, n)+R^{D} \max [0, a-k] .
$$

This constraint implies that entrepreneurs with a low level of accumulated assets may be constrained and run their firms below their optimal size. Nevertheless, because of the properties assumed for $Q$, becoming an entrepreneur has a future value. That is, an entrepreneur is willing to sacrifice current consumption for having the possibility of starting a career that increases the firm's return over time. The way to obtain this return profile is by investing a large share of his income and wealth so as to relax the credit constraint in order to run the firm at its optimal size.

There are two frictions that affect the production decisions of entrepreneurs. The first distortion is characterized by the financial constraint (6) which makes some entrepreneurs run projects with size lower than what it is efficient. To understand the role of the financial constraint, let $R$ be the opportunity cost of capital which could be equal to $R^{L}$ or $R^{D}$ depending on whether the entrepreneur is a borrower or a depositor. For an unconstrained agent, the first order conditions with respect to inputs are given by

$$
\int u^{\prime}(c)\left[z^{\prime} f_{k}(k, n)-R\right] Q\left(z, d z^{\prime}\right)=0
$$

and

$$
\int u^{\prime}(c)\left[z^{\prime} f_{n}(k, n)-w\right] Q\left(z, d z^{\prime}\right)=0 .
$$

These two expressions produce the optimal capital to output ratio, q. For the production function (1), the optimal capital to output ratio is given by

$$
q \equiv \frac{k^{u}(z)}{n^{u}(z)}=\left(\frac{\alpha}{1-\alpha}\right) \frac{w}{R}
$$


Notice $q$ is independent of the individual state of the agent. Also, implicit here is the fact that because the agent is unconstrained, the choice of capital and labor do not depend on the asset level of the agent and only change with the productivity signal, z. However, it may occur that the financial constraint (6) does not hold for this choice of inputs, that is,

$$
w n^{u}(z)+R k^{u}(z)>(1-\delta+R) a+\underline{z} f\left[k^{u}(z), n^{u}(z)\right] .
$$

In this case, it is still optimal to keep the same capital to labor ratio $q$ and the constrained level of labor (and, implicitly, the level of capital) is determined from the expression

$$
w n^{c}(a)+R q n^{c}(a)=(1-\delta+R) a+\underline{z} f\left[q n^{c}(a), n^{c}(a)\right] .
$$

The skill and asset levels of an individual affect both his occupational decision and the financial constraints he faces if he becomes an entrepreneur. Giving a skill level, $z$, the larger the asset position of an agent the more benefits he has from becoming an entrepreneur. So, for each value of the signal $z$ there is a critical level of assets, call it $a^{s}(z)$, such that for $a>a^{s}(z)$ the agent decides to be an entrepreneur and for $a<a^{s}(z)$ the agent decides to be a worker. Furthermore, for a given skill level, the financial constraint is more likely to bind as the assets of the agent are lower. So, there is another level of assets, call it $a^{c}(z)$, such that, if the agent is an entrepreneur, for $a>a^{c}(z)$ he is financially unconstrained and for $a<a^{c}(z)$ the agent is financially constrained. Thus, entrepreneurs with skill $z$ and assets in the interval $\left[a^{s}(z), a^{c}(z)\right]$ are constrained and their demands of inputs are an increasing function of accumulated assets. Entrepreneurs with assets $a>a^{c}(z)$ have demands of inputs which are independent of the level of wealth and only depend on the productivity signal $z$. By the same intuition, given the level of assets, as the productivity signal gets larger, it is more profitable to become an entrepreneur and it is more likely that entrepreneurs are financially constrained. This means that any shock making financial markets more liquid or credit cheaper will reallocate assets towards constrained entrepreneurs and will, in general, increase the aggregate level of productivity of the economy.

The second distortion is the spread between borrowing and lending rates due to the reserve requirement. For an unconstrained entrepreneur who is borrowing, the relevant opportunity cost of capital is $R^{L}$. This means that his optimal capital to labor ratio is

$$
q^{L} \equiv \frac{k^{L u}(z)}{n^{L u}(z)}=\left(\frac{\alpha}{1-\alpha}\right) \frac{w}{R^{L}}
$$


where $k^{L u}$ is the capital demand of a lender who is unconstrained and $n^{L u}$ is the corresponding demand for labor. On the other hand, an entrepreneur who is also unconstrained but has assets in excess of his needs, will be a depositor and the corresponding capital to labor ratio will be

$$
q^{D} \equiv \frac{k^{D u}(z)}{n^{D u}(z)}=\left(\frac{\alpha}{1-\alpha}\right) \frac{w}{R^{D}}>q^{L} .
$$

For these financially unconstrained agents, independent of whether they are borrowers or depositors, their input decisions only depend upon their productivity signal. However, because of the gap between $R^{L}$ and $R^{D}$, there may be agents who would like to be borrowers at the high capital to labor ratio $q^{D}$ and depositors at the low capital to labor ratio $q^{L}$. In such a case, these entrepreneurs are constrained to have $k^{A}=a .^{7}$

\subsection{Outside the stationary equilibrium}

As pointed out above, proportional changes in the government liabilities are neutral. Also, changes in government liabilities that permanently move the ratio of liquid to illiquid liabilities $(h / b)$ are associated with different steady states. In this section, we look at how the economy moves between these stationary situations. In particular, assume the economy is at the stationary equilibrium characterized by the number $h$. Then, the central bank announces unexpectedly a permanent change in this number, say, an increase to $\widehat{h}>h$. In the period of the announcement, the total amount of liabilities $(X)$ is fixed, so, this change could be achieved by increasing liquid liabilities to $\widehat{H}=\widehat{h} X>H$ and reducing illiquid liabilities to $\widehat{B}=(1-\widehat{h}) X<B$ through an open market operation. After that, the liabilities of the central bank are permanently split between liquid and illiquid liabilities in order to match the new values of $\widehat{h}$ and $\widehat{b}$ satisfying $\widehat{h}+\widehat{b}=1$.

The unexpected nature of the announcement means that in the first period of the transition, the population starts with the distribution of assets and productivities of the old steady state, $\lambda$. With the new supplies of government liabilities, the conditions to be satisfied in the first period of the transition are the market

\footnotetext{
${ }^{7}$ The nature of this constraint is different from the financial restriction mentioned before and it is just a consequence of the gap between borrowing and lending rates imposed by the reserve requirement. Nevertheless, in the simulations we run in the following section it turns out that agents for which $k=a$ represent a very small fraction of entrepreneurs (less than 1 percent of all entrepreneurs).
} 
clearing condition for deposits

$$
\frac{1}{\rho} \widehat{H}=P_{1} \int_{W_{1}} a \lambda(d a \times d z)+P_{1} \int_{E_{1}} \max \left[0, a-k_{1}(a, z)\right] \lambda(d a \times d z),
$$

and the market clearing condition for loans

$$
\widehat{L}=P_{1} \int_{E_{1}} \max \left[0, k_{1}(a, z)-a\right] \lambda(d a \times d z),
$$

with

$$
\widehat{H}+\widehat{B}=X=H+B
$$

In these expressions, the subscript 1 denotes that these are variables for the first period of the transition and $\widehat{L}$ is the new supply of loans to entrepreneurs computed from the balance sheet of commercial banks

$$
\left(\frac{1}{\rho}-1\right) \widehat{H}=\widehat{L}+\widehat{B}
$$

Notice the split between entrepreneurs and workers (the indices $W_{1}$ and $E_{1}$ ) may change also in response to the different composition of government liabilities.

Equations (7) and (8) are the market clearing conditions to find the price level $P_{1}$ and the interest rate $R_{1}$ for the new values of reserves $(\widehat{H})$ and government debt $(\widehat{B})$. Remember from section 3.2 that a proportional change in government liabilities is necessary for monetary policy to be neutral. In the current case, financial intermediaries learn that the supply of reserves have increased which gives them the possibility of expanding credit. However, the government is borrowing less through debt so banks will have to give these credits to entrepreneurs. Given that the interest rate is a cost to entrepreneurs borrowing credits, the only way to convince them to borrow more is by reducing the lending rate. This change produces several effects. First, some of the idle assets that were not used before are now available to finance productive capital. Also, lower interest rates make entrepreneurs borrow more assets, use more capital and produce more. With the larger use of capital the demand for labor moves up and wages rise. Given the concavity of the production function, how much the marginal productivity of labor, and therefore wages, increases depends on how labor is allocated between highly productive, constrained firms and low productive, unconstrained firms. Finally, there is a reduction in the gap between borrowing and lending rates which, by itself, enhances efficiency further.

As a consequence of these movements, the distribution of assets after the first period changes because prices and allocations have been altered. From that point 
on, all variables and distributions will converge to the stationary equilibrium associated with the new monetary policy. To solve for this transition, we have to work with the sequence of values of normalized prices $p_{t}$, real wages $w_{t}$ and interest rates $R_{t}$ that satisfy the conditions (7) and (8) together with the evolution of the distribution of assets. Once the sequence of $p_{t}$ is computed, we can calculate the sequence of prices from

$$
P_{t}=p_{t} X_{t}
$$

These computations cannot be carried out analytically. We perform them in the following numerical exercise.

This basic mechanism just described resembles the one used in the limited participation literature. In this literature, nonneutrality of money is achieved by imposing two assumptions: (i) the nominal interest rate represents a cost to firms, and (ii) households providing funds to firms cannot react to changes in monetary policy. Thus, an injection of money by the central bank means that entrepreneurs have also to absorb a larger amount of liquidity which forces interest rates to decrease and have the same expansionary effects on economic activity. Because loans to entrepreneurs are the only asset on the balance sheet of commercial banks, condition (ii) is needed in these models so that households cannot undo the monetary policy change. As compared with the limited participation literature, we substitute condition (ii) by imposing a reserve requirement together with the existence of government debt. In our model, the fractional reserve requirement links the amount of liquidity in the economy to the supply of reserves while borrowing by the government determines which part of that liquidity has to be absorbed by entrepreneurs.

\section{Simulations}

For the simulations we use a logaritmic utility and a Cobb-Douglas production function. Periods are assumed to be quarters. Table 2 includes the value of the main parameters of the model. As we see by the value of $\theta$, there exists decreasing returns to entrepreneurs' projects. These values are standard in the literature. The reserve requirement $\rho$ is 3 percent in the Unites States. The parameters related to the distribution of ability shocks $(Z)$ and transition matrices for them are included in Table 3.

Table 4 reports the values of some key variables for the initial steady state (column SS1). We start with a value of $h$ which implies a ratio of liquid to illiquid liabilities of $h / b=0.10$. The economy rests in an equilibrium where the capital to output ratio is 9.61. Furthermore, 12 percent of the population are entrepreneurs and 88 percent workers. Of all entrepreneurs, 23 percent are constrained in their 
borrowing activities. The lending rate is 1.39 percent per quarter while the deposit rate is 1.30 percent.

We conduct the experiment of permanently increasing the ratio of government's liquid to illiquid liabilities from 0.10 to 0.11 . This monetary policy change can be achieved by an open market operation where the central bank buys government bonds outright in exchange for reserves. Column SS2 of Table 4 shows the new steady state corresponding to that ratio. Such a change is associated with a larger normalized price level. It is also associated with a smaller interest rate and inflation rate, but the changes in these variables as well as the real magnitudes are insignificant.

Although the two steady states are very close to each other, the transition between them is far from being negligible due to the financial constraint that some entrepreneurs face. Notice that in both steady states, aggregate real assets are larger than aggregate productive capital, $K$. In particular, entrepreneurs only use 75 percent of all real assets as capital in the first stationary equilibrium and 77 percent in the second one. As mentioned above, the difference between assets and the capital stock used in production is a consequence of the intervention of the government in borrowing some of the units of account created by commercial banks and signals one of the inefficiencies of the economy. It is of no surprise that the gap between assets and capital is reduced when the central bank proportionally decreases the importance of its certificates of deposits. The last column of Table 4 reports the value of the corresponding ratios found in the data. We observe all the numbers to be very close to their empirical counterpart.

Agents in this economy do not anticipate the monetary policy change. This means that the distribution of assets across agents at the first period of the transition is equal to the one corresponding to the old steady state. Figures 2 to 7 present the transition of an economy between the two steady states. They show transitions for each variable as the percentage change with respect to the initial steady state (except interest rates that are presented as differences with respect to the old steady state). In the graphs, period 0 corresponds to the old steady state while the exogenous monetary policy change occurs on period 1. Figure 2 shows that output rises on impact by around 1.1 percent of the value of the old steady state. This variable stays at levels between 1.1 and 1.3 percent larger than the original stationary equilibrium for around six quarters. Then it slowly decays towards the new steady state which is close to the old one. In the same figure we see that both capital and labor increase over the transition. We also observe that assets decrease over the transition monotonically. The reasons for these movements are explained below.

Figure 3 shows that on impact, interest rates decrease by 26 basis points at an annual rate. Notice this is the typical change the Fed usually engineers to stimulate the US economy in recessions. At the same time, wages increase and stay above 
the old steady state during the whole transition. This means that the increase in labor is originated through an increase in the demand for labor. The normalized price increases slowly towards the new steady state level. Figure 4 includes the evolution of real financial assets. There is a reduction of deposits at the same time as an increase in loans. As the government reduces its borrowing, the reduction in interest rates puts downward pressure on the demand for real deposits as well as the supply of loans increase as financial intermediaries try to divert resources to entrepreneurs. This is why Figure 1 showed a reduction in the asset levels of the economy.

Figures 5 and 6 give an idea of the internal mechanism generating this transition. Figure 5 presents the evolution of the fraction of entrepreneurs who are financially constrained. At the initial steady state, this variable took a value of 23 percent. On impact, it changes to 22 percent and stays low relative to the old steady state. This is a consequence of the reduction in interest rates which relaxes the financial constraint for some entrepreneurs.

In Figure 6, we compare the responses of three entrepreneurs who differ on their initial level of accumulated assets. The top panel is generated as follows. First, we look at the wealth distribution of assets in the initial steady state and compute the average wealth level of the entrepreneurs in the bottom docile. Second, we follow the trajectory of an entrepreneur with that level of assets who keeps a productivity of $z=2.25$ permanently. We choose this number because the largest fraction of entrepreneurs (54 percent) is concentrated at that skill level. Because of his low level of initial assets, this agent starts financially constrained. So he enters in a path where he is accumulating assets and, given that he keeps a high level of productivity, eventually becomes unconstrained. Third, we look at the trajectory of this same agent but only after the monetary shock hits the economy in the first period. The graph is the ratio of the two trajectories. So, the figure says that this agent hires 3 percent more labor in the first period after the shock than what he would otherwise have hired had the shock not occurred. The middle panel represents the same exercise with an entrepreneur with the same skills but with the average capital level of all entrepreneurs. The bottom panel represents the entrepreneur with the average asset level of the top docile of the entrepreneurs. To understand these graphs it is important to notice that these agents had different paths in the original steady state. The poor entrepreneur was accumulating assets to reach a level that will make him unconstrained and run his firm at the optimal level. He reached such a level of assets in period 12. Thus, as he was increasing his wealth, so did his demand of capital and labor and his production. On the contrary, the average and rich entrepreneurs were not constrained by their wealth and were running their firms at the optimal level. The input demands for these agents only depended on their skill level. As we maintained their productivities constant they had constant profiles for output and inputs. 
During most of the transition, the reduction in the interest rate together with the increase in wages, makes all agents work with a larger capital to labor ratio. For the constrained entrepreneur, the decrease in the cost of capital outweighs the wage increase and his financial constraint is relaxed. This allows him to hire more inputs ( 6 percent more capital and 3 percent more labor on impact) and to produce more (3.4 percent more on impact) than what he did in the old steady state. As he accumulates more assets, his financial constraint is also relaxed in the future which allows him to maintain higher levels of production and to propagate the effects of the shock over time. However, profits are small compared to his wealth and assets still take the same time to reach the level in which he is unconstrained (12 periods).

The average entrepreneur also takes advantage of the fall in the interest rate since he is a borrower as well. He hires more capital and is able to produce more. However, because he is financially unconstrained, the only effect that works for him is the change in prices. This is why their use of inputs expand much less than the constrained entrepreneurs. As Figure 6 shows, the initial increase in his capital is about half of the one for the constrained entrepreneur. This means that the marginal productivity of labor increases little for him and he does not change labor much on impact (about six times less than the constrained entrepreneur). Finally, the change in the relative price of inputs makes the rich entrepreneur clearly worse off. He reduces his labor demand and consequently his output. ${ }^{8}$

Finally, Figure 7 presents the evolution of idle capital. It shows a decrease in unused resources of above 8 percent. This is the reason why output and capital used rise on impact. The increase in the ratio of liquid to illiquid government liabilities reduces the cost of using capital and productive entrepreneurs can use more funds to acquire capital. It is in this sense in which we believe this mechanism works under any other reason for having idle capacity, such as uncertainty about demand at the time of capacity decisions or costs of operating at full capacity. The idea is that there exists this other cost related to the financing of productive capital which an expansionary monetary policy is able to reduce.

\section{Conclusions}

This paper analyzes two stylized facts, namely, the possibility of monetary shocks significantly affecting economic activity and the persistence of these effects over time. We first present evidence on how monetary policy shocks associated with the Fed changing the composition of government liabilities may have an impact on real activity through its effects on capacity utilization. We then build up an

\footnotetext{
${ }^{8}$ Capital on this panel shows no movement because the grid at those levels of wealth is very wide.
} 
economy where the monetary shocks propagate in a similar way as we find in the data. Interestingly, the internal propagation mechanism in the model does not rely on any sort of stickiness or adjustment costs. Our interpretation is based on the way credit is created and how the monetary conditions in an economy affect the process of financial intermediation.

In our model, there is a distribution of agents who accumulate assets that may be used as capital for production purposes. Capital is distributed among agents through the use of nominal units of account created by financial intermediaries. Entrepreneurs with a low level of assets borrow these units of account to obtain extra capital for their firms. In this sense, the nominal interest rate represents a cost of production. Furthermore, there is no possibility of default in financial contracts which force entrepreneurs to have enough collateral to cover potential negative profits. Thus, borrowers with very low levels of accumulated assets relative to their investment needs may be constrained in their borrowing activities.

When creating credit, banks have to satisfy reserve requirements. The monetary authority provides these banks with two types of assets: reserves and bonds. We show that the relevant policy variable to determine the level of interest rates is the ratio of liquid (reserves) to illiquid (bonds) government liabilities. An expansionary monetary policy is associated with an increase in this ratio. Thus, an outright open market operation by which the central bank buys government bonds in exchange for reserves frees financial resources that can be used by entrepreneurs to increase the amount of capital they employ. In particular, this monetary policy shock relaxes the financial restriction of constrained entrepreneurs allowing them to borrow more capital and to produce more. As the distribution of assets among agents changes in time, this disturbance sets in motion a response of the economy that resembles an expansionary phase of the cycle.

The basic propagation mechanism is the ability of constrained entrepreneurs to accumulate more assets which relaxes their financial constraint also in the future and allows them to maintain higher levels of production. Additionally, in our simulation profits are small as compared to wealth so the distribution of asset ownership takes time to change. This also contributes to propagating shocks over time. We have shown that this mechanism is able to generate sizeable effects on real activity with responses that are persistent as we observe in the data. 


\section{References}

[1] Alvarez Lois, P. (2003): "Capacity Utilization and Monetary Policy" Bank of Spain Working Paper 0306.

[2] Bernanke, B. S. and M. Gertler (1989): "Agency Cost, Net Worth and Business Fluctuations", American Economic Review 79 (1), 14-31.

[3] Bernanke, B. S., M. Gertler and S. Gilchrist (1999): "The Financial Accelerator in a Quantitative Business Framework" in J. Taylor and M. Woodford (eds.) Handbook of Macroeconomics, vol. 1, 1341-93. Elsevier Science, NorthHolland.

[4] Board of Governors of the Federal Reserve System (2002): Flow of Funds Accounts for the United States. Available at http://www.federalreserve.gov/releases/z1/current/data.htm.

[5] Boháček, R. (2002): "Financial Intermediation and Entrepreneurial Activity", unpublished manuscript.

[6] Canova, F. and J. Pina (1999): "Monetary Policy Misspecification in VAR Models," CEPR Discussion Paper 2333.

[7] Carlstrom, C. T. and T. S. Fuerst (1997): "Agency Costs, Net Worth, and Business Fluctuations: A Computable General Equilibrium Analysis", American Economic Review 87 (5), 893-910.

[8] Christiano, L., M. Eichenbaum, and C. Evans (1996): "The Effects of Monetary Policy Shocks: Evidence from the Flow of Funds" Review of Economics and Statistics 78 (1), 16-34.

[9] Cooley, T., R. Marimon and V. Quadrini (2001): "Aggregate Consequences of Limited Contract Enforceability", unpublished manuscript.

[10] Cooley, T. and V. Quadrini (1999): "Monetary Policy and the Financial Decision of Firms", unpublished manuscript.

[11] Fagnart, J., O. Licandro and F. Portier (1999): "Firm Heterogeneity, Capacity Utilization and the Business Cycle" Review of Economic Dynamics 2 (1), 433455 .

[12] Fuerst, T. S. (1995): "Monetary and Financial Interactions in the Business Cycle" Journal of Money, Credit and Banking 27 (4), 1321-1338. 
[13] Hubbard, R. G. (1995): "Is There a 'Credit Channel' for Monetary Policy?" Federal Reserve Bank of St. Louis Review 77 (3), 63-77.

[14] Jermann, U. and V. Quadrini (2003): "Stock Market Boom and the Productivity Gains of the 1990s", unpublished manuscript.

[15] Kiyotaki, N. and J. Moore (1997): "Credit Cycles" Journal of Political Economy 105 (2), 211-48.

[16] Kiyotaki, N. and J. Moore (2001): "Liquidity, Business Cycles, and Monetary Policy" unpublished manuscript.

[17] Lucas, R. E. Jr. (1978): "On the Size Distribution of Business Firms" Bell Journal of Economics 9, 508-523.

[18] Lucas, R. E. Jr. (1980): "Equilibrium in a Pure Currency Economy" in Models of Monetary Economics, edited by J. H. Kareken and N. Wallace. Federal Reserve Bank of Minneapolis.

[19] Menner, M. and H. Rodríguez Mendizábal (2003): "On the Effects from Monetary (Policy?) Shocks", unpublished manuscript.

[20] Monge-Naranjo, A. (2001): "Financial Markets, Creation and Liquidation of Firms and Aggregate Dynamics", unpublished manuscript, Northwestern University.

[21] Quadrini, V. (1999): "Entrepreneurship, Saving and Social Mobility" Duke University and CEPR working paper.

[22] Stokey, N. L., R. E. Lucas and E. C. Prescott (1989): Recursive Methods in Stochastic Dynamics, Cambridge, Harvard University Press. 


\section{Appendix A: Data Sources}

We used several sources of data. Financial data for liquid government liabilities $(H)$, government bonds $(B)$, and loans $(L)$ were taken from the Federal Reserve Board's Flow of Funds Accounts for the United States. ${ }^{9}$ We first constructed a series of seasonally adjusted from the unadjusted levels (Tables L in the Accounts) and the adjusted increments (Tables A in the Accounts). Then, we defined these three variables as follows: ${ }^{10}$

$H=$ Liquid government liabilities equal Depository institution reserves (Table 108 , code 713113000$)$ plus Vault cash of commercial banks $(108,723025000)$, and Currency outside banks (108, 713125005).

$B=$ Illiquid government liabilities equal U.S. government securities of financial institutions (109, 763061005; 114, 443061005; 115, 473061005; 116, 603061005; 117, $543061005 ; 118,513061005 ; 119,573061005 ; 120,223061005 ; 121,633061005 ; 122$, $653061003 ; 123,553061103$ and $563061103 ; 124,403061005 ; 126,673061705 ; 129$, 643061703; and 130, 663061005) plus Municipal securities (109, 763062005; 114, 443062005; 116, 603062003; 117, 543062003; 118, 513062003; 120, 223062003; 121 , $633062440 ; 122,653062003 ; 123,553062003 ; 124,403062005$; and 130, 663062003). $L=$ Loans are equal to Corporate equity $(109,763064105 ; 114,443064075 ; 116$, $603064105 ; 117,543064105 ; 118,513064003 ; 119,573064105 ; 120,223064005 ; 122$, 653064000; 123, 553064103 and 563064103; and 130, 663064003), plus Corporate bonds $(109,763063005 ; 114,443063005 ; 116,603063003 ; 117,543063005 ; 118$, 513063003 ; 119, 573063005; 120, 223063005; 121, 633063003; 122, 653063003; 123,553063003 and $563063003 ; 124,403063003 ; 129,643063003 ; 130,663063003$; and 131, 503063003), plus Mortgages (109, 763065005; 114, 443065005; 115, 473065105; 116, 603065103; 117, 543065003; 119, 573065003; 120, 223065005; 124 , $403065005 ; 125,413065005 ; 126,673065005 ; 127,613065000 ; 128,623065003$; and 129, 643065003), plus Open market paper $(109,763069175 ; 114,443069105 ; 115$, 473069103; 116, 603069103; 117, 543069100; 119, 573069105; 120, 223069103; 121, $633069175 ; 122,653069100 ; 124,403069603 ; 130,663069103$; and 131, 503069105), plus Consumer credit loans (109, 723066000; 114, 443066003; 115, 473066000; 126, 673066000; and 127, 613066005), plus Other loans and advances (109, 763068005; 114,$443069505 ; 124,403069255 ; 126,673069005$; and 127, 613069500).

$D=$ Deposits are just the sum of the three variables specified above $(D=H+$ $B+L)$.

\footnotetext{
${ }^{9}$ See Board of Governors [4].

${ }^{10}$ Here we report the number of the table and the code. The complete reference for the table includes an $\mathrm{L}$ for Tables $\mathrm{L}$ and an $\mathrm{F}$ for Tables $\mathrm{A}$. The complete codes start with FL for Tables L and with FA for Tables A.
} 
The ratios defined in the paper (that is, $h, b$ and $h / b$ ) had large trends until the beginning of the 1990s when they stabilized. This is the moment when the Fed began to target interest rates. To make the numbers in Table 3 meaningful, the column "Data" in that table was computed from a sample starting in the first quarter of 1990 and ending in the third quarter of 2002, which was the last date available.

Data on interest rates were taken from the Statistical Release H.15 of the Board of Governors of the Federal Reserve System (available at the elctronic address http://www.federalreserve.gov/releases/h15/data.htm). These interest rates are: $R^{D}=$ Interest on deposits. It is computed from the 3-month Eurodollar deposits (London).

$R^{L}=$ Interest on loans. It is the computed from the Bank prime loan rate.

The sources for the rest of the variables are as follows:

$F E D S E C=$ Fed holdings of government securities. This is equal to the seasonally adjusted series of US government securities held by the Federal Reserve Banks (Table L108, code 713061005 of the Flow of Funds Accounts).

$N B R=$ Nonborrowed reserves. This series is taken from the Statistical Release H.6 of the Board of Governors of the Federal Reserve System (available at http://www.federalreserve.gov/releases/h6/hist/).

Capacity utilization rate. This series represents the capacity utilization rate in the Manufacturing industry and was taken from Tables 7 and 8 of the Statistical Release G.17 of the Board of Governors of the Federal Reserve System (available at http://www.federalreserve.gov/releases/g17/download.htm).

National account variables were taken from the FRED database (available at http://research.stlouisfed.org/fred2/).

Share of entrepreneurs. This number is taken from the Panel Study of Income Dynamics (PSID), for the year 1994.

Gini coefficients for wealth and income are also taken from the PSID, 1989. 


\section{Appendix B: Tables and Figures}

Table 1

Regression of policy variables on monetary shock

\begin{tabular}{ccc}
\hline & \multicolumn{2}{c}{ Dependent variable, $y(t)$} \\
\cline { 2 - 3 } & FEDSEC & NBR \\
\hline constant & 2.2433 & 0.5935 \\
& $(5.914)$ & $(1.637)$ \\
$y(t-1)$ & -0.1154 & 0.2764 \\
& $(-1.227)$ & $(1.385)$ \\
$y(t-2)$ & 0.0837 & -0.2190 \\
& $(0.966)$ & $(-1.764)$ \\
$y(t-3)$ & -0.0092 & 0.0887 \\
& $(-0.136)$ & $(0.981)$ \\
$y(t-4)$ & -0.1388 & 0.0927 \\
& $(-1.662)$ & $(0.919)$ \\
Monetary shock & 0.4925 & 0.8070 \\
& $(3.436)$ & $(2.959)$ \\
\hline
\end{tabular}

Results from OLS regression of variable $y(t)$ on four lags and the monetary shock. T-statistics based on White's heteroskedasticity consistent variance matrix in parenthesis. 
Table 2

Parameters of the model values

\begin{tabular}{clc}
\hline Symbol & Meaning & Value \\
\hline$\beta$ & Time preference & 0.985 \\
$\delta$ & Depreciation rate & 0.016 \\
$\theta$ & Span of managerial control & 0.825 \\
$\alpha$ & Capital elasticity of output/ $\theta$ & 0.340 \\
$\rho$ & Reserve requirement & 0.030 \\
\hline
\end{tabular}


Table 3

Parameters of the distributions of shocks

Ability shocks Z

\begin{tabular}{lllllllll}
\hline 0.00 & 0.50 & 1.00 & 1.50 & 2.00 & 2.25 & 2.50 & 2.75 & 3.00
\end{tabular}

Distribution $\psi$ of worker's ability shocks

\begin{tabular}{lllllllll}
\hline 0.00 & 0.05 & 0.88 & 0.03 & 0.02 & 0.00 & 0.01 & 0.00 & 0.01
\end{tabular}

Transition matrix $Q$ for entrepreneur's ability shocks

\begin{tabular}{lllllllll}
\hline 1 & 0 & 0 & 0 & 0 & 0 & 0 & 0 & 0 \\
1 & 0 & 0 & 0 & 0 & 0 & 0 & 0 & 0 \\
0.2250 & 0 & 0.7500 & 0.0250 & 0 & 0 & 0 & 0 & 0 \\
0.0100 & 0 & 0.0750 & 0.8000 & 0.0250 & 0 & 0 & 0 & 0 \\
0.0500 & 0 & 0 & 0.0750 & 0.8500 & 0.0250 & 0 & 0 & 0 \\
0.0250 & 0 & 0 & 0 & 0.1000 & 0.8500 & 0.0250 & 0 & 0 \\
0.0125 & 0 & 0 & 0 & 0 & 0.1125 & 0.8500 & 0.0250 & 0 \\
0.0125 & 0 & 0 & 0 & 0 & 0 & 0.1125 & 0.8500 & 0.0250 \\
0.0125 & 0 & 0 & 0 & 0 & 0 & 0 & 0.1325 & 0.8500 \\
\hline
\end{tabular}


Table 4

Steady states

\begin{tabular}{clccc}
\hline Symbol & Meaning & SS1 & SS2 & Data $^{*}$ \\
\hline$h / b$ & Reserves over government bonds & 0.10 & 0.11 & 0.12 \\
$h$ & Reserves over assets & 0.02 & 0.02 & 0.03 \\
$b$ & Government bonds over assets & 0.23 & 0.21 & 0.24 \\
\hline$R^{D}$ & Interest on deposits (percent) & 1.30 & 1.28 & 1.17 \\
$R^{L}$ & Interest on loans (percent) & 1.39 & 1.37 & 1.83 \\
$p$ & Normalized price level & 0.07 & 0.08 & - \\
$\mu$ & Inflation (percent) & 0.32 & 0.29 & 0.54 \\
\hline$K / Y$ & Productive capital over output & 9.61 & 9.65 & 12.2 \\
$K / d$ & Capacity utilization rate & 0.75 & 0.77 & 0.82 \\
$H /(P Y)$ & Reserves over nominal output & 0.30 & 0.29 & 0.24 \\
$B /(P Y)$ & Gov. bonds over nominal output & 2.98 & 2.64 & 1.94 \\
\hline & Share of entrepreneurs & 0.12 & 0.12 & 0.10 \\
& Share of constrained entrepreneurs & 0.23 & 0.21 & - \\
& Gini wealth & 0.63 & 0.63 & 0.77 \\
& Gini income & 0.27 & 0.26 & 0.45 \\
\hline
\end{tabular}

* See Appendix A for a description of the data. 
FIGURE 1

Aggregate levels

Capital $\left({ }^{*}\right)$, Output (s), Labor (o), Assets (x)

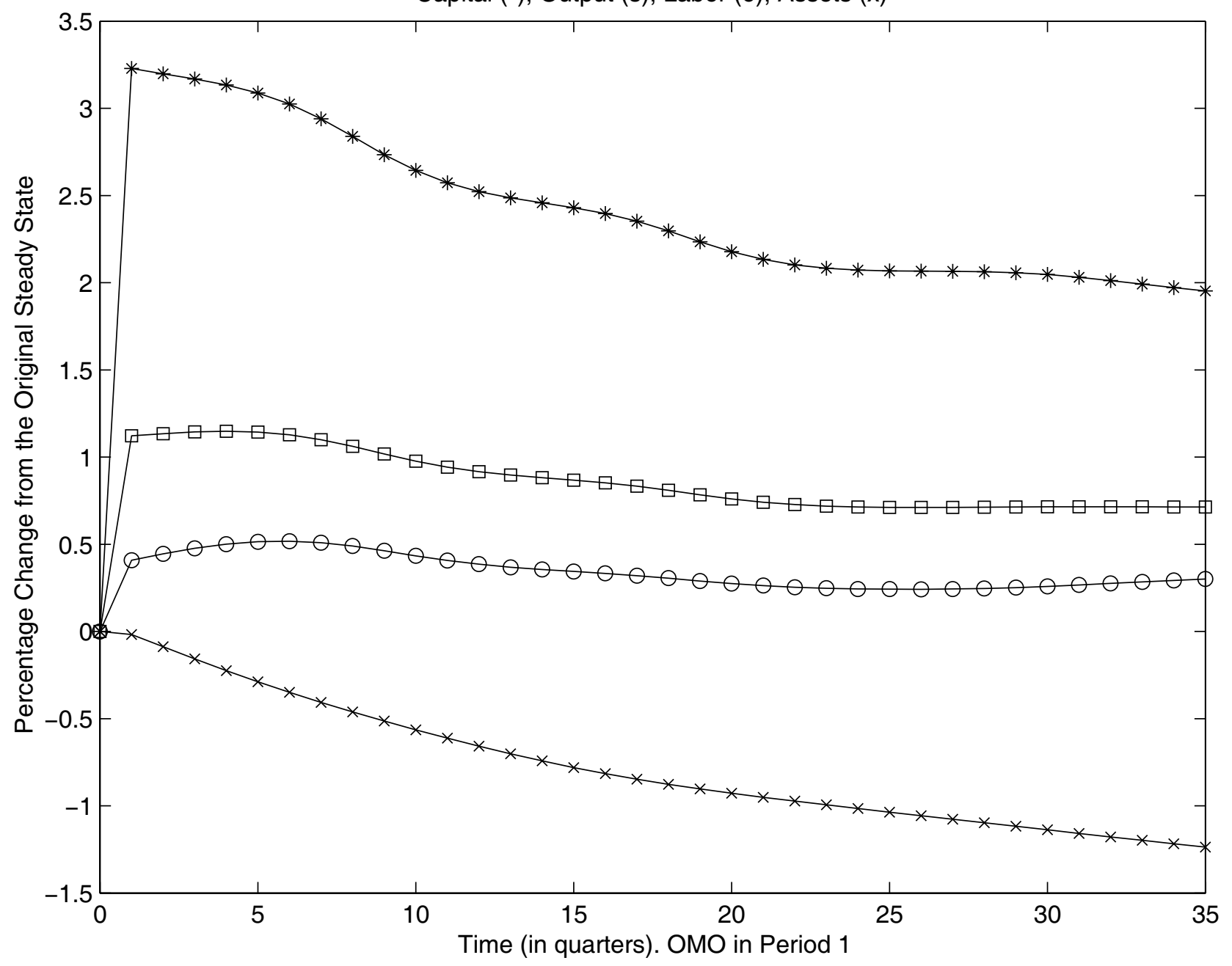




\section{FIGURE 2}

Interest rate on loans

Basis Point Change from the Original Steady State

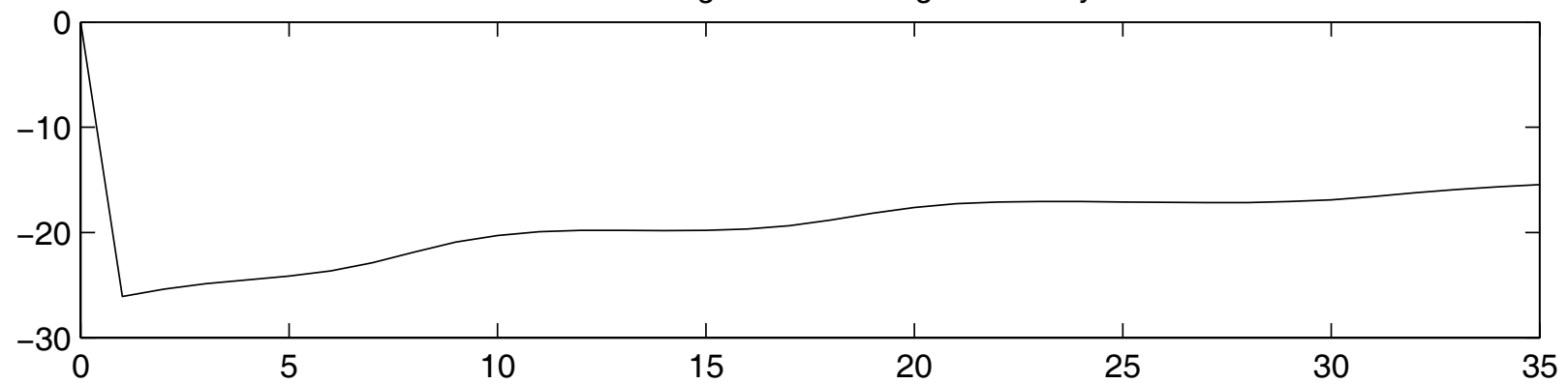

Wage: Percentage Change from the Original Steady State
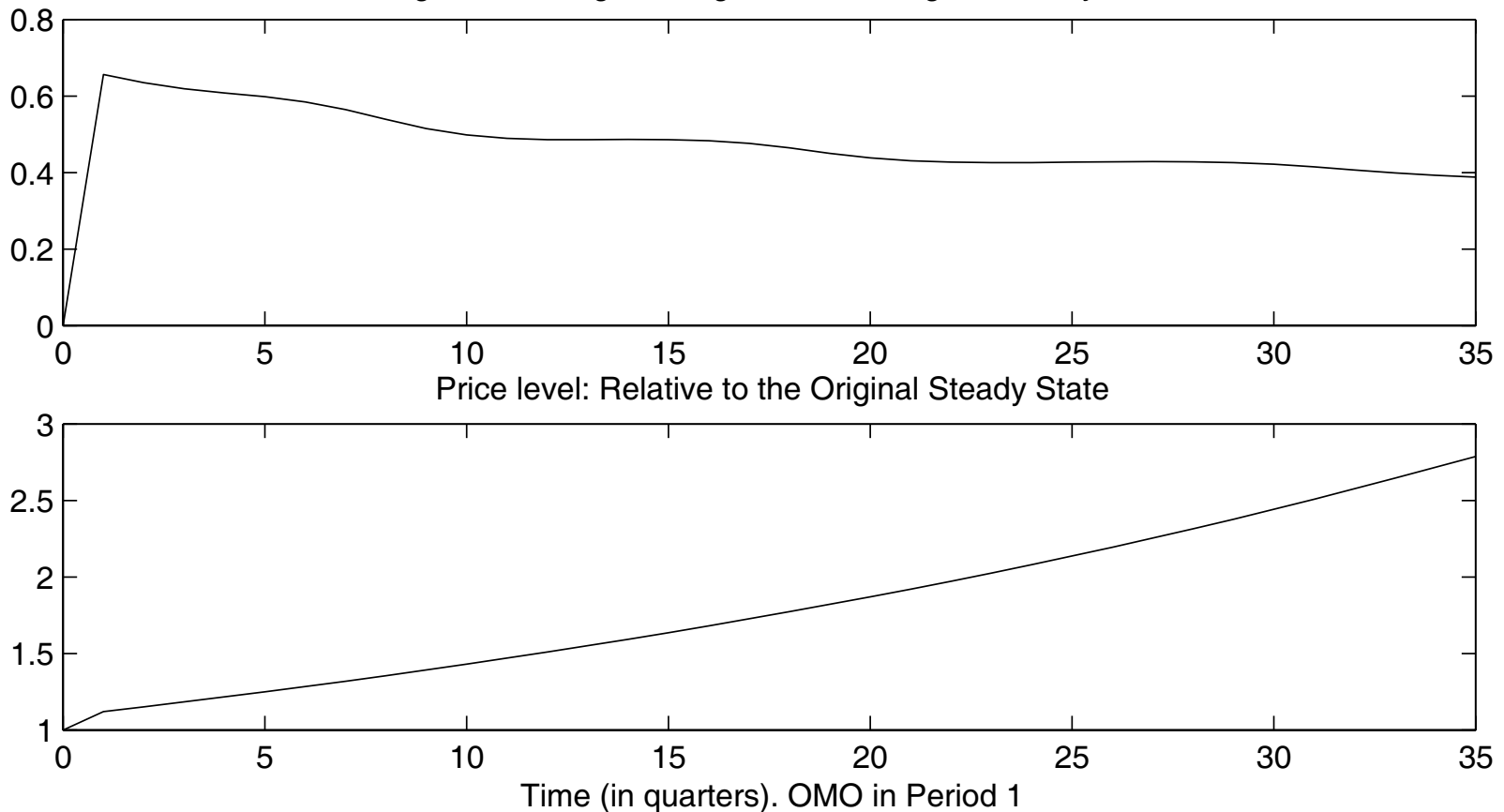


\section{FIGURE 3}

Loans and Deposits

Loans (x). Deposits: Total (s), by workers $\left(^{*}\right)$, by entrepreneurs (o).

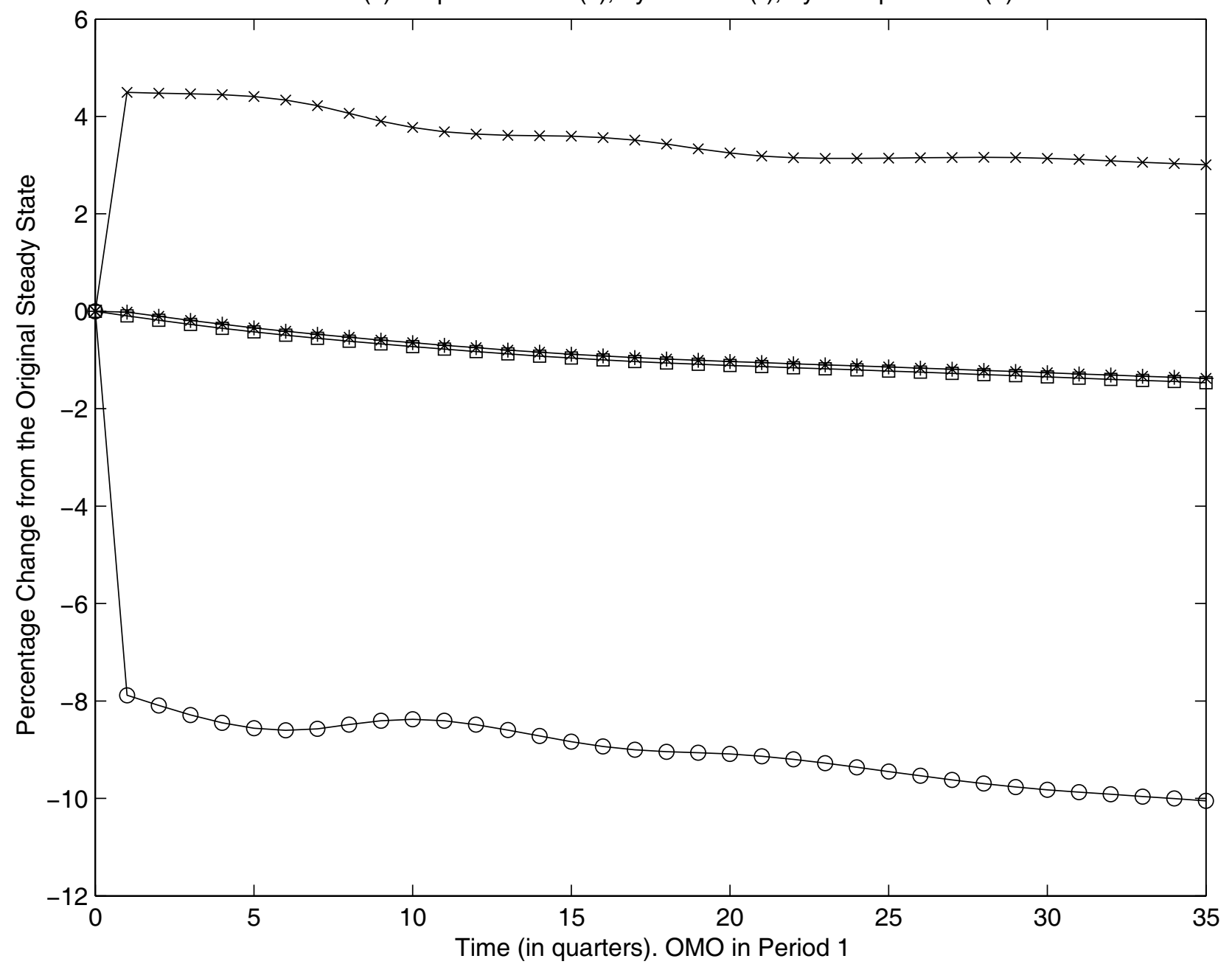




\section{FIGURE 4}

Financially Constrained Entrepreneurs Share in the Population of Entrepreneurs

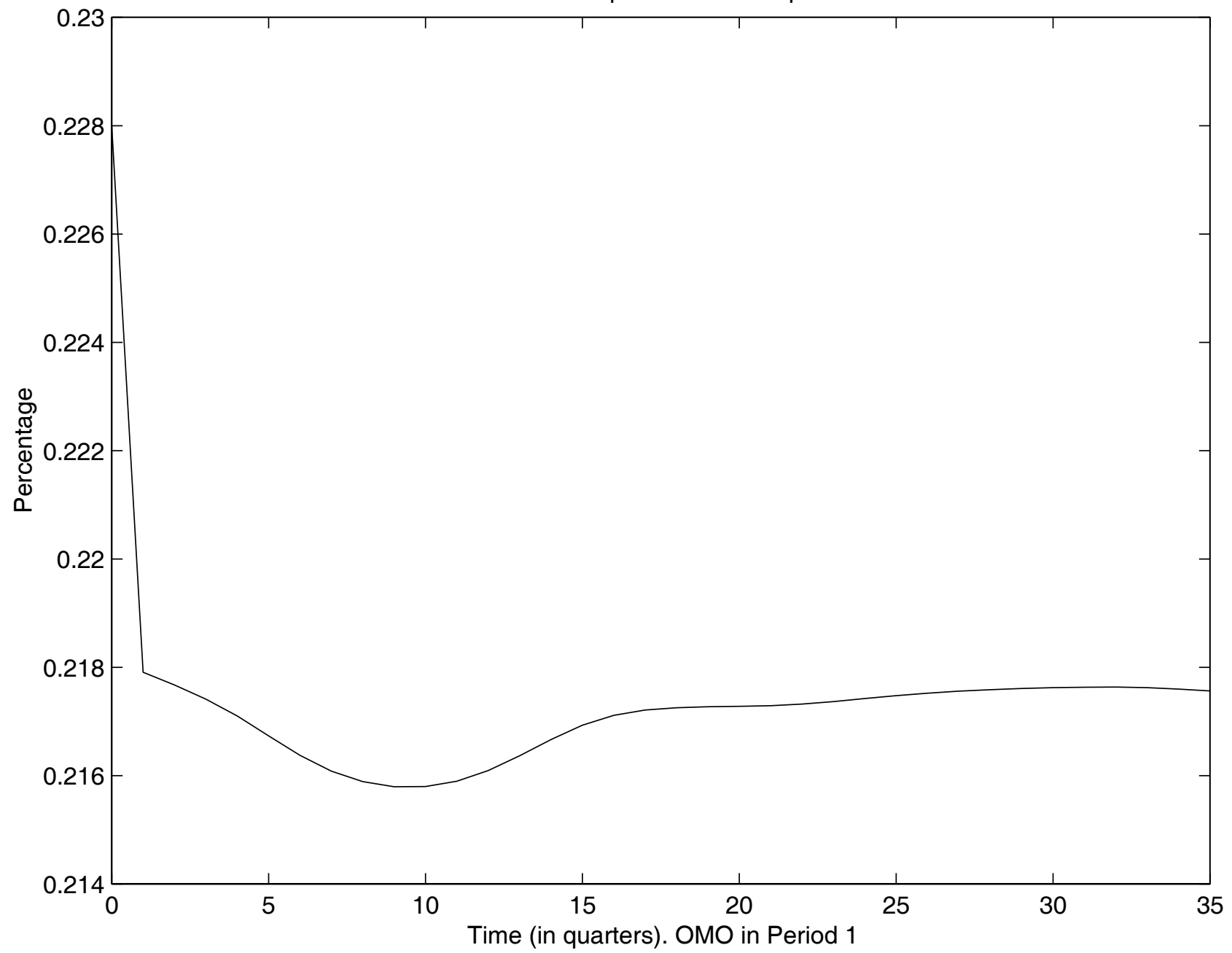


FIGURE 5

Entrepreneurial Decisions

Bottom Docile Entrepreneur (Borrower, Unconstrained from $\mathrm{t}=12$ )
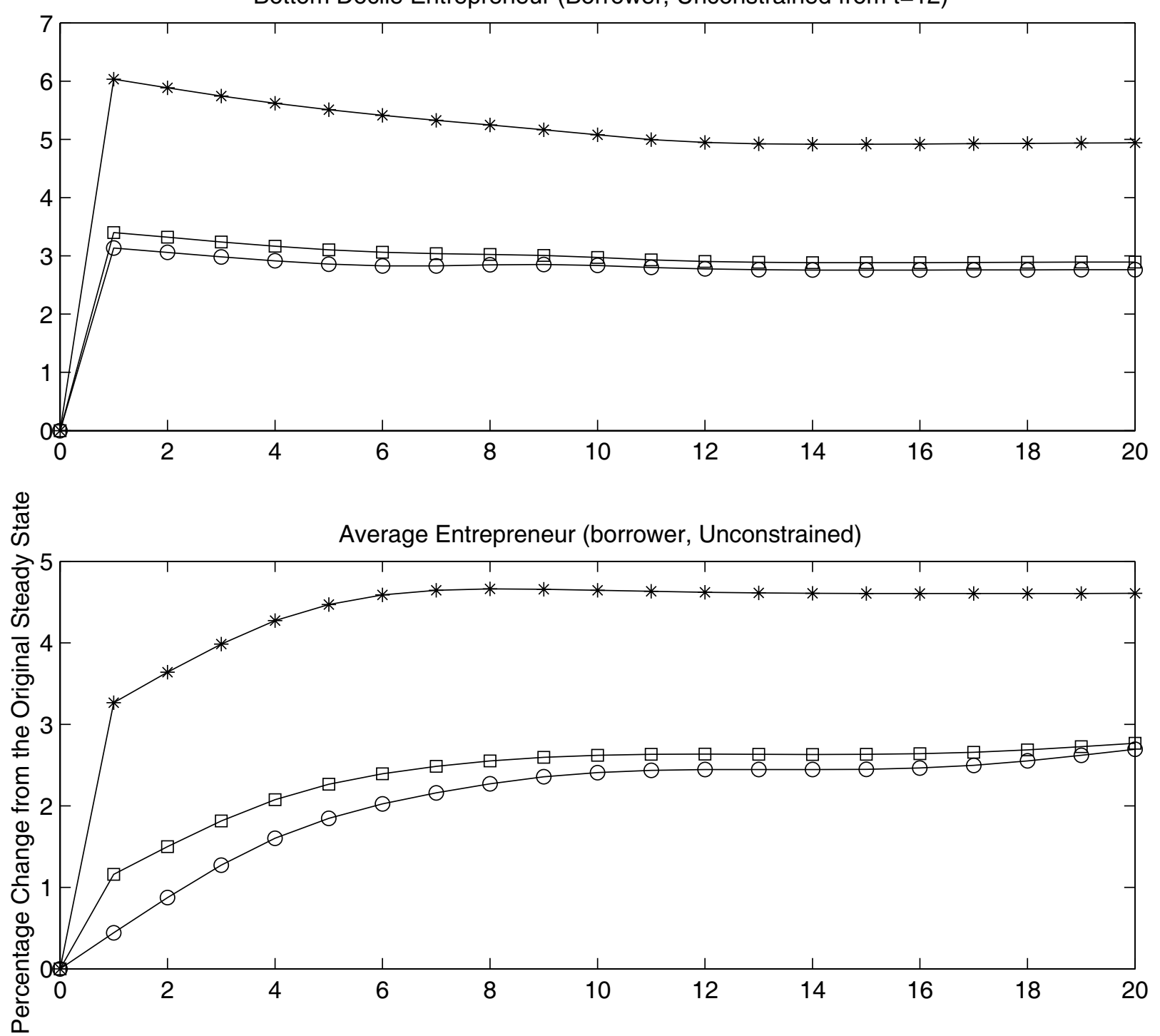

Top Docile Entrepreneur (Lender, Unconstrained)

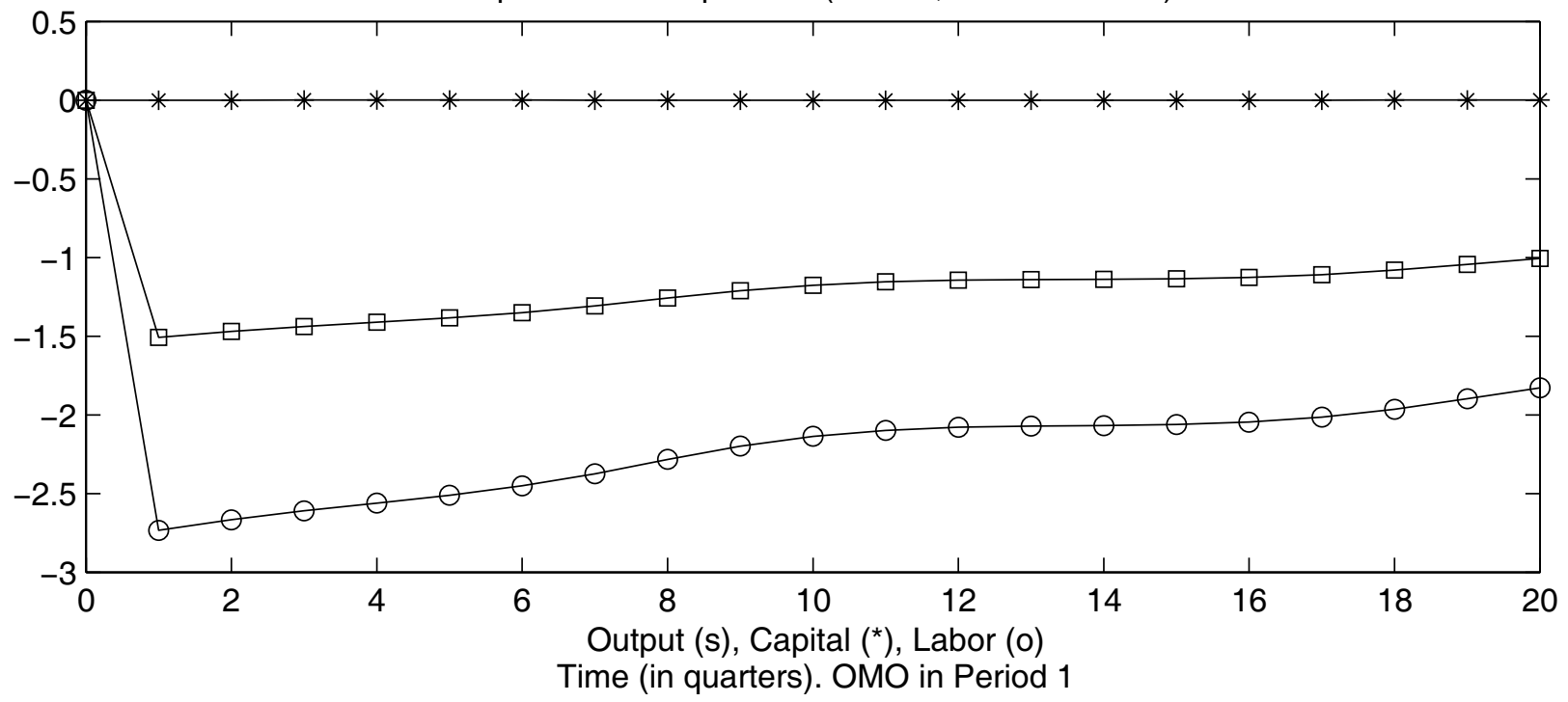


FIGURE 6

Idle Capital

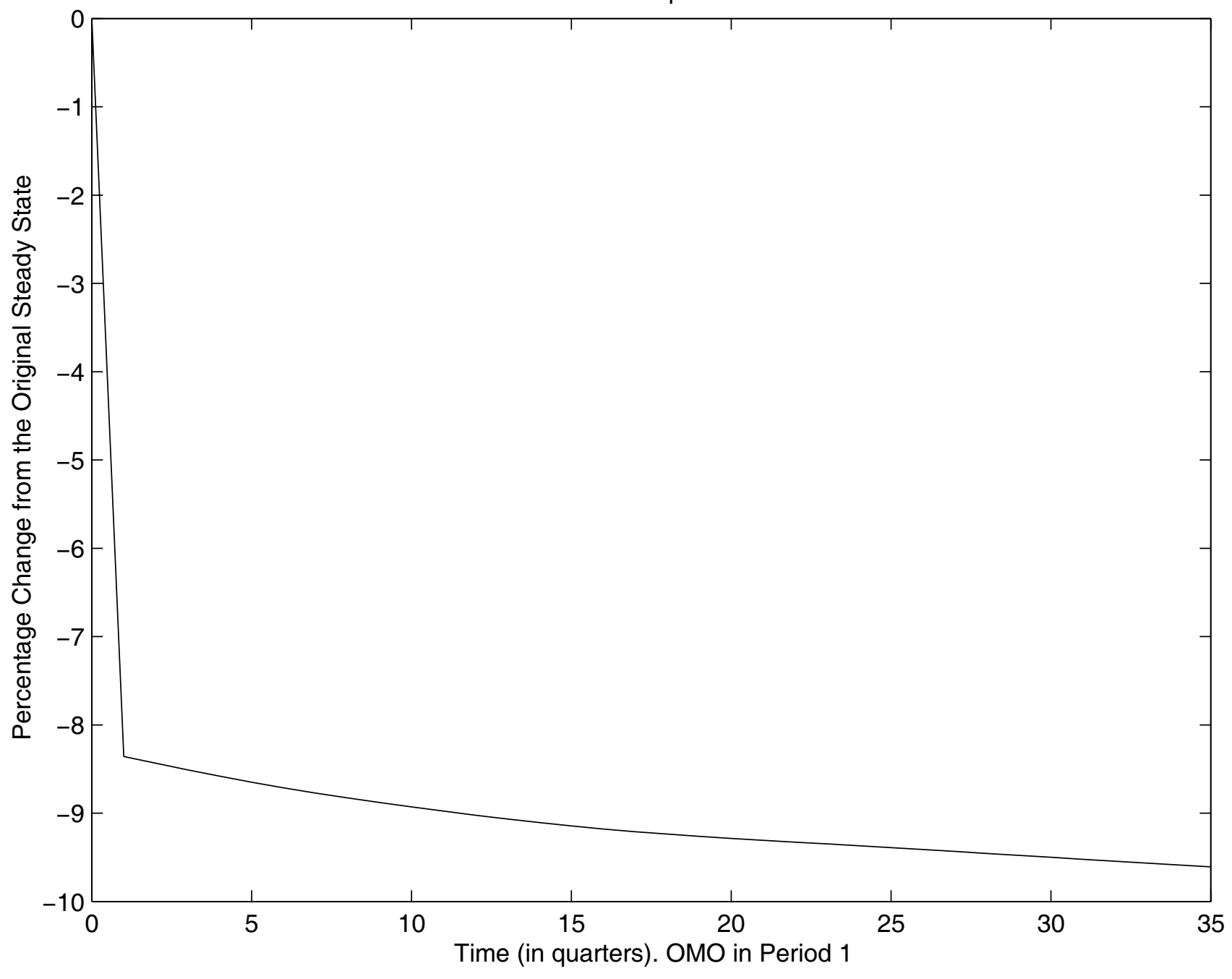

